\title{
Mechanisms of coagulative necrosis in malignant epithelial tumors (Review)
}

\author{
ROSARIO A. CARUSO ${ }^{1}$, GIOVANNI BRANCA ${ }^{1}$, FRANCESCO FEDELE ${ }^{1}$, ELEONORA IRATO ${ }^{1}$, \\ GIUSEPPE FINOCCHIARO $^{1}$, ANTONIO PARISI ${ }^{2}$ and ANTONIO IENI ${ }^{1}$
}

Departments of ${ }^{1}$ Human Pathology and ${ }^{2}$ Surgical Science, University of Messina, Messina I-98125, Italy

Received October 9, 2013; Accepted July 1, 2014

DOI: 10.3892/ol.2014.2345

\begin{abstract}
Histological tumor necrosis (TN) has been reported to indicate a poor prognosis for different human cancers. It is generally accepted that $\mathrm{TN}$ results from chronic ischemic injury due to rapid tumor growth. However, whether insufficient tumor vascularization and inadequate tumor cell oxygenation are the only factors causing TN remains controversial. Mitotic catastrophe is considered to occur as a result of dysregulated/failed mitosis, leading to cell death. We hypothesize that mitotic catastrophe, induced by hypoxic stress, may lead to the TN which is observed in high grade carcinomas. The current review describes the morphological features of TN in malignant epithelial tumors. In addition, evidence regarding the involvement of mitotic catastrophe in the induction of TN in human carcinomas is discussed.
\end{abstract}

\section{Contents}

1. Introduction

2. Definition of apoptosis and TN

3. Detection of TN

4. Morphological variants of coagulative TN

5. TN and fibrotic focus

6. $\mathrm{TN}$ in invasive adenocarcinomas

7. $\mathrm{p} 53$

8. Mitotic catastrophe in anticancer therapy

9. Pathogenesis of TN

\section{Introduction}

Recent studies have shown that tumor necrosis (TN) influences metastasis-free survival in patients exhibiting neoplasms $(1,2)$.

Correspondence to: Professor Rosario A. Caruso, Department of Human Pathology, University of Messina, 1 Via Consolare Valeria, Messina I-98125, Italy

E-mail: rosariocaruso@tin.it

Key words: histologic tumor necrosis, mitotic catastrophe, histopathology, carcinoma
In particular, $\mathrm{TN}$ has been reported to indicate poor prognosis in lung (3), breast $(4,5)$, thyroid $(6)$, colorectal $(7,8)$, pancreatic (9) and renal (10-16) malignancies. Therefore, it has been proposed that the presence/absence of TN must be indicated in any histopathological report $(12,14)$, as this type of assessment has a high rate of reproducibility among pathologists $(9,12)$.

It is generally accepted that $\mathrm{TN}$ is a result of chronic ischemic injury due to rapid tumor growth. Jain and Carmeliet (17) suggested that intratumoral mechanical stresses, resulting from tumor cell proliferation, cause focal large-vessel obstruction, leading to ischemic intratumoral infarcts. The compression, exerted by surrounding neoplastic cells on the microvasculature, is considered to be spatially and temporally heterogeneous (18) and this may explain the uneven distribution of TN. However, whether insufficient tumor vascularization and inadequate tumor cell oxygenation are the only factors causing TN remains controversial. We hypothesize that hypoxia may indirectly induce coagulative necrosis in tumor cells harboring p53 mutations via mitotic catastrophe. Mitotic catastrophe is a cell death mechanism, which occurs as a result of dysregulated/failed mitosis that may be accompanied by morphological alterations, including micronucleation, multinucleation and abnormal mitoses.

In this review, the morphologic features of $\mathrm{TN}$ in malignant epithelial tumors are investigated. In addition, the associations between hypoxia, mitotic catastrophe and $\mathrm{TN}$ are briefly reviewed within the framework of our hypothesis.

\section{Definition of apoptosis and TN}

Depending on the lethal stimulus, tumor cells may die as a result of distinct cellular death mechanisms, including apoptosis and necrosis. The term 'apoptosis' was coined by Kerr et al (19) to distinguish the phenomenon as a mechanism of cell death that is morphologically separate from coagulative necrosis. Ultrastructural features of apoptosis include margination and condensation of chromatin, nuclear fragmentation in apoptotic bodies (corresponding to the histological terms, pyknosis and karyorrhexis), and ruffling of the plasma membrane, which maintains integrity until the final stages of the process (19-21). Phagocytosis of apoptotic bodies is carried out by professional phagocytes, including macrophages and dendritic cells, and non-professional 'neighboring' phagocytes, including epithelial cells, endothelial cells, smooth 
muscle cells and fibroblasts. By contrast, necrosis is characterized by cellular swelling, which is accompanied by chromatin flocculation, dilatation of the mitochondria and endoplasmic reticulum, plasma membrane rupture and eventual shedding of the cytoplasmic contents into the extracellular space, with subsequent inflammation (20-21).

\section{Detection of TN}

According to the recommendations of the Nomenclature Committee on Cell Death (NCCD) (21-23), electron microscopy remains the 'gold standard' for identification of the specific features of cells undergoing death. However, the detection of cell death must be based on at least two techniques, one to reveal morphological changes and the second to demonstrate biochemical changes (21). For example, pathologists use combined immunohistochemical methods and light microscopy to identify dying necrotic cells. Histologically, coagulative necrosis appears acellular and stains homogeneously with red eosin. However, careful examination shows retention of the general architectural pattern of the tissue, despite the death of its constituent elements. Coagulative necrosis is also characterized by an abrupt transition from viable to necrotic cells without an interposed zone of granulation tissue or hyalinized tissue between the viable and necrotic cells (21). Generally, these histological observations are supplemented with electron microscopy images to identify the morphological characteristics of dying necrotic cells. In addition, Tdt-mediated dUTP nick end labeling (TUNEL) and anti-active caspase-3 staining are often used to identify apoptotic cell death (21). Usually, cells that stain positively for TUNEL but negatively for active caspase-3 are considered to be necrotic (24). On the other hand, there are no specific positive discriminative biochemical markers for the detection of necrosis in vitro or in vivo. However, it has been demonstrated that certain candidate necrotic biomarkers, including high-mobility group box 1 protein and cyclophilin $\mathrm{A}$, are released by cells dying from secondary necrosis following apoptosis (24).

\section{Morphological variants of coagulative TN}

Peritheliomatous necrosis and comedo-type necrosis may be considered as morphological variants of coagulative TN. The term peritheliomatous necrosis refers to a microscopic pattern which is characterized by large areas of coagulative necrosis with sheets or cords of viable tumor cells surrounding a centrally disposed blood vessel (Fig. 1) (18). The term 'comedo' describes the appearance of compressed ducts exuding necrotic material, often observed in ductal carcinoma in situ (DCIS) of the breast, which is a neoplastic expansion of ductal lining cells confined by the basement membrane (25). As blood vessels remain in the stromal compartment, DCIS occurs in an avascular microenvironment and inevitably develops hypoxic regions near the oxygen diffusion limit, due to persistent proliferation of intraepithelial tumor cells. Pathologists have distinguished two types of DCIS, comedo and non-comedo (25), based on the presence of necrosis, which is often associated with microcalcifications in the center of the breast ducts (25).
A pattern similar to comedo-type necrosis, characteristically found in DCIS of the breast, has also been identified in invasive carcinomas. It is characterized by the presence of well-circumscribed epithelial nests containing central necrotic material, including neuroendocrine carcinomas; carcinoma arising in pleomorphic adenoma, duct carcinomas of the salivary glands; cervical carcinoma in situ with features of impending invasion; and basaloid squamous carcinoma of the lung, salivary glands, esophagus, anal canal and sinonasal tract (25). Therefore, coagulative necrosis and its variants (peritheliomatous and comedo-type necrosis) are usually observed in epithelial tumors, in situ and invasive, characterized by a solid growth pattern.

\section{TN and fibrotic focus}

Following a certain period of time, coagulative necrosis may be replaced by colliquative necrosis, in which the cellular structures are broken down by proteolitic enzymes released from ruptured lysosomes and similar enzymes released by infiltrating inflammatory cells (20). Finally, colliquative/coagulative necrosis is replaced by a scar-like area, defined as the fibrotic focus (26). It appears as a radially expanding fibrosclerotic core and consists of loose, dense or hyalinized collagen bundles and a variable number of fibroblasts (26). In addition, elastic tissue may be abundant. The arrangements of fibroblasts or collagen fibers forming fibrotic foci differ from that of the surrounding stroma, which is more ordered (26). The presence of a fibrotic focus was found to positively correlate with disease progression, increased tumor size, lymph node metastases and a poor outcome in breast, colorectal and pancreatic cancer (26-28).

\section{6. $\mathrm{TN}$ in invasive adenocarcinomas}

Colliquative necrosis, dirty necrosis and intraglandular necrotic debris are usually identified in invasive adenocarcinomas (29-35). In these tumors, necrosis may remain confined to single neoplastic glands, whereas in other areas it may involve neoplastic glands and intervening stroma. The term 'dirty necrosis' is used to describe the presence of intraglandular eosinophilic material frequently in combination with necrotic cell debris and neutrophils (29). This intraglandural material stains positively with periodic acid-Schiff and expresses the transmembrane glycoprotein MUC1 (29). Furthermore, dirty necrosis has been identified in colorectal adenocarcinomas and is often accompanied by segmental necrosis of the glandular lining (29). Foci of dirty necrosis are also common in pulmonary metastases of colonic carcinomas, but are rarely observed in primary lung adenocarcinomas (36). Necrotic areas involving the stroma and glands are frequently infiltrated by neutrophils in a pattern similar to that observed in colliquative necrosis (Fig. 2) (7). Notably, mucinous adenocarcinomas are characterized by MUC2 overexpression and the absence of dirty necrosis (37). Colliquative and/or dirty necrosis are predominantly found in MUC1-positive adenocarcinomas of the pancreas (38) and colorectum (29), whereas the absence of necrotic phenomena is characteristically found in MUC2-positive mucinous adenocarcinomas of the gastrointestinal tract $(36,39)$. 


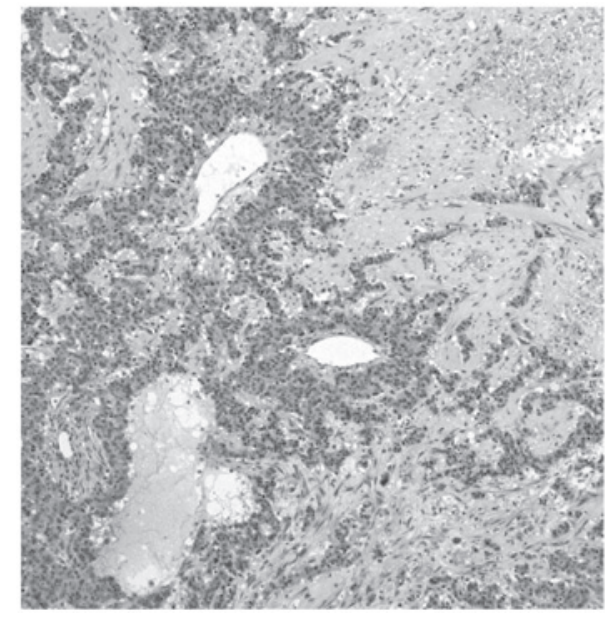

Figure 1. Gastric carcinoma exhibiting a solid growth pattern. Peritheliomatous necrosis is characterized by sheaths of viable tumor cells surrounding a centrally disposed blood vessel. (Stain, hematoxylin and eosin; magnification, $\mathrm{x} 100$ ).

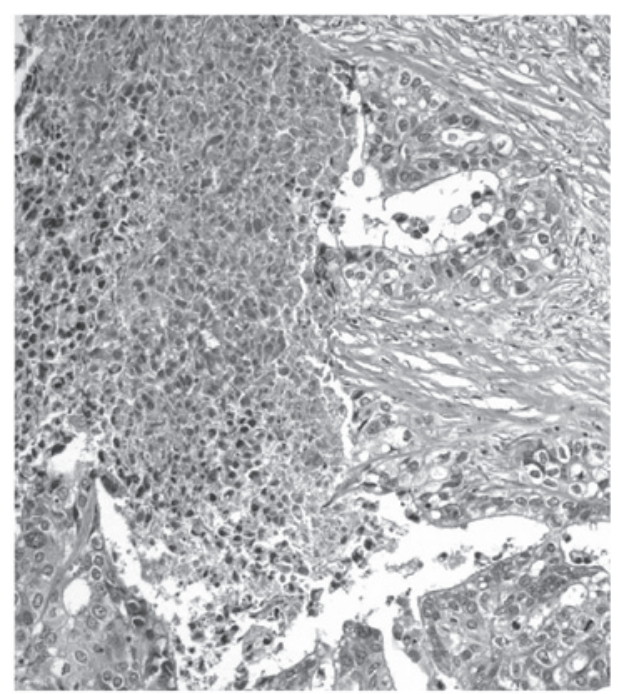

Figure 2. Gastric adenocarcinoma: Necrotic areas involving the stroma and epithelium are infiltrated by neutrophils. (Stain, hematoxylin and eosin; magnification, $\mathrm{x} 100)$.

\section{7.p53}

p53 acts as a guardian of the genome, protecting cells against cancer (40). In response to a variety of genotoxic stresses (DNA-damaging agents, UV damage, antimicrotubule agents and hypoxia), the p53 protein promotes cell-cycle arrest, which is necessary to repair any DNA damage, or apoptosis, if repair cannot be achieved (Fig. 3) (40). Cell-cycle arrest may be used to repair any damage, whereas apoptosis is a genetically controlled response whereby cells commit suicide when repair cannot be achieved. These cellular responses allow p53 to inhibit tumorigenesis and genomic instability (40). Furthermore, when p53 is mutated, it accumulates at the nuclear level and the cell-cycle checkpoint becomes defective. Thus, a cell may enter mitosis prematurely, prior to the completion of DNA replication or DNA damage repair. This aberrant mitosis may lead to apoptosis or necrosis (41).

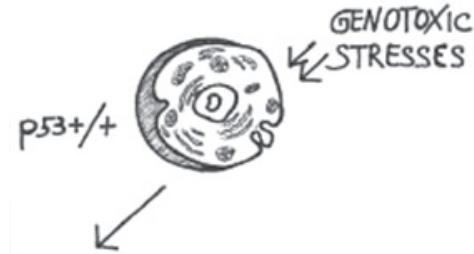

DNA REPAIR

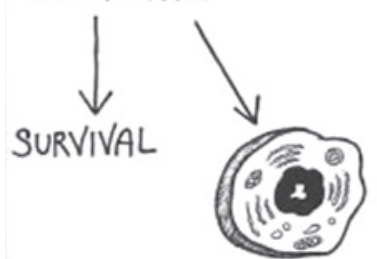

APOPTOSIS

Figure 3. Schematic representation of the pathway leading to apoptosis in wild-type p53 (+/+) cells following genotoxic stress.

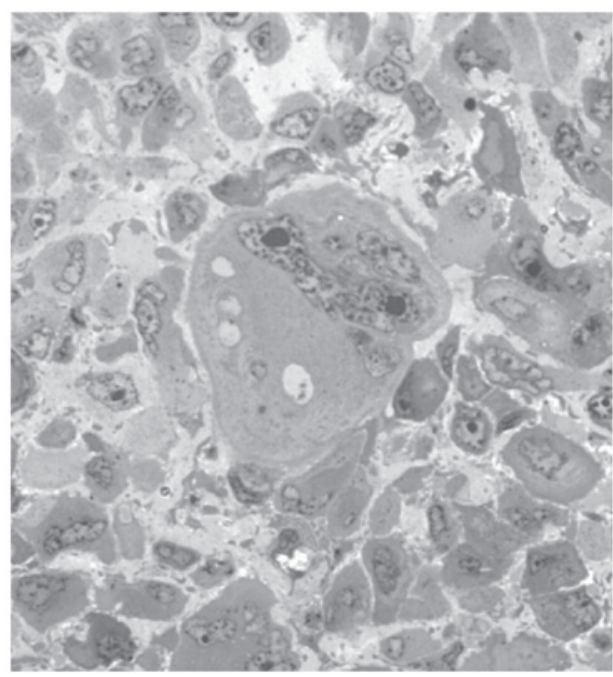

Figure 4. Semi-thin section of pleomorphic giant cell carcinoma of the thyroid. Certain giant tumor cells exhibit multiple nuclei and micronuclei. (Stain, Giemsa; magnification, x400).

Of note, mitotic catastrophe is not considered a form of cell death, but rather an irreversible trigger for cell death (22).

The p53 tumor suppressor gene is mutated in $~ 50 \%$ of all human cancers. Following severe genotoxic damage, numerous p53-mutated tumors undergo mitotic catastrophe (41-44). According to NCCD, mitotic catastrophe refers to cell death that is triggered by aberrant mitosis and executed during mitosis or in the subsequent interphase (22). Mitotic catastrophe is morphologically characterized by anisocytosis and anisokaryosis (heterogeneity in cytoplasmic and nuclear size, respectively), presence of micronuclei (derived from chromosomes and/or chromosome fragments that have been irregularly distributed between daughter nuclei) and multinucleation (two or more nuclei with similar or heterogeneous sizes in a single cell, as a result of failed separation during cytokinesis) (Fig. 4) (22). Morphological features associated with mitotic catastrophe may be observed in pleomorphic, giant cell carcinoma, a tumor without any identifiable 


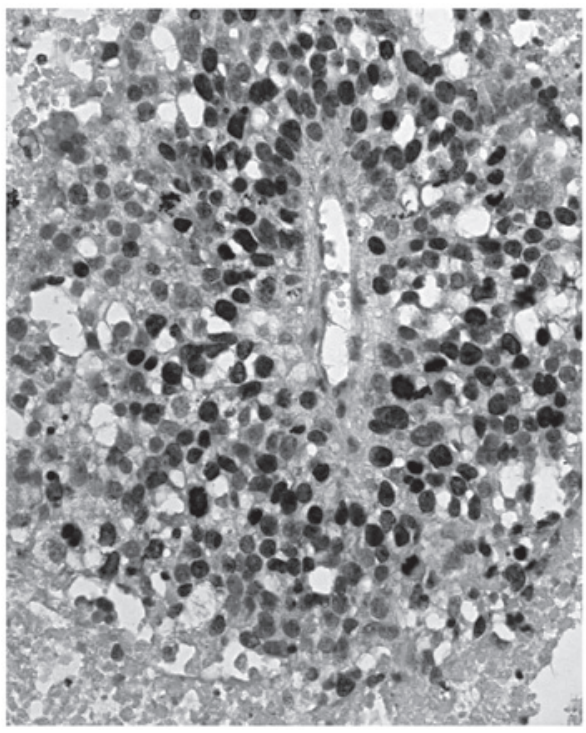

Figure 5. Gastric carcinoma: A close association between peritheliomatous necrosis, atypical mitoses and numerous cycling Ki-67-positive tumor cells is observed (stain, Ki-67 immunoperoxidase; magnification, x200).

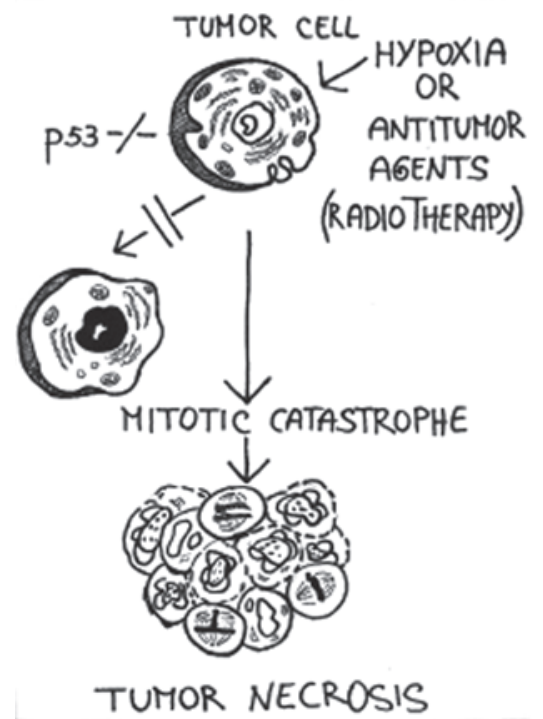

Figure 6. Proposed model of tumor necrosis in mutated p53 (-/-) tumor cells. Ischemia, a known genotoxic stress, may induce necrosis via mitotic catastrophe variably accompanied by atypical mitoses, anisocytosis, anisokaryosis, multinucleation and micronucleation.

glandular, squamous or any other type of differentiation (45). It consists of sheets of highly undifferentiated pleomorphic cells, often with areas of coagulative necrosis (22) with numerous bizarre/multinucleated cells (46-48) and many abnormal mitotic figures. Pleomorphic, giant cell carcinomas are highly malignant tumors that are most commonly found in the lungs, breast, pancreas and thyroid (22).

\section{Mitotic catastrophe in anticancer therapy}

Mitotic catastrophe has been characterized as the predominant form of cell death induced by ionizing radiation, and occurs in response to several anticancer drugs $(49,50)$. Since preoperative chemotherapy is being used more frequently in the management of advanced tumors, pathologists must be aware of the resultant morphological effects, which may result in difficulties in tumor typing and grading and in the identification of residual neoplasia $(51,52)$. The morphological features of lung, breast and ovarian cancers treated with chemotherapy include nuclear and cytoplasmic alterations and pronounced stromal changes $(52,53)$. Nuclei exhibit significant enlargement with extremely irregular outlines, and occasionally appear similar to multinucleated giant cells $(52,53)$, a feature associated with mitotic catastrophe. Nuclear size has been shown to represent a useful prognostic indicator in ovarian and breast cancer, and therefore an increased nuclear size post-chemotherapy may influence the results if this measurement is used as a predictor of outcome (53). Post-chemotherapy tumor cells are observed singularly or in small clusters, often without tubular differentiation, and mitotic activity is rare (53). Therefore, preoperative chemotherapy causes difficulty in tumor grading, which is based on cytological and architectural features, as well as mitotic activity.

\section{Pathogenesis of TN}

It is hypothesized that $\mathrm{TN}$ is caused by chronic ischemia (i.e. hypoxia, low $\mathrm{pH}$, low glucose and high lactate) within tumors, due to vascular collapse, high interstitial pressure and/or rapid tumor growth exceeding its blood supply. Anemia, the most common cancer-associated morbidity, further reduces the blood capacity for $\mathrm{O}_{2}$ transportation (54), and it is an adverse prognostic factor for survival, which is independent of tumor type (55). The contiguous or sheet-like nature of the necrosis indicates that the cause of death is due to ischemic injury, affecting a field or group of tumor cells, supplied or drained by a single vessel (18). The subsequent necrosis suggests that the large feeding artery or exit vein becomes obstructed, leading to an arterial or a venous infarct (18). By contrast to this hypothesis, it has been revealed that $\mathrm{TN}$ frequently occurs within regions that display relatively increased microvessel density (56). However, there are tumors in which coagulative necrosis is rare, although the tumor stage is advanced. For example, the lowest frequency of TN is observed in mucinous adenocarcinomas of the gastrointestinal tract (36). Furthermore, Tollefson et al (57) revealed that renal carcinomas exhibiting coagulative necrosis also exhibited relatively high proportions of proliferative Ki-67-positive tumor cells. Similar findings have been demonstrated in gastric carcinomas (45). Fig. 5 shows the morphological association between peritheliomatous necrosis, atypical mitoses and high proportion of cycling Ki-67 immunoreactive tumor cells.

We hypothesize that hypoxia, a known genotoxic factor, may indirectly induce $\mathrm{TN}$ via mitotic catastrophe in tumor cells harboring p53 mutations. A similar pathway has been suggested for TN occurring in vivo following treatment with anticancer drugs or radiation $(42,44,58)$. Our hypothesis for the association between hypoxia, mitotic catastrophe and TN is shown in Fig. 6. Further studies regarding the mechanisms associated with TN may yield useful insights into epithelial malignant tumor biology and improve patient management. 


\section{References}

1. Richards CH, Mohammed Z, Qayyum T, Horgan PG and McMillan DC: The prognostic value of histological tumour necrosis in solid organ malignant disease: a systematic review. Future Oncol 7: 1223-1235, 2011.

2. Caruso R, Parisi A, Bonanno A, et al: Histologic coagulative tumour necrosis as a prognostic indicator of aggressiveness in renal, lung, thyroid and colorectal carcinomas: A brief review Oncol Lett 3: 16-18, 2012

3. Swinson DE, Jones JL, Richardson D, Cox G, Edwards JG and O'Byrne KJ: Tumour necrosis is an independent prognostic marker in non-small cell lung cancer: correlation with biological variables. Lung Cancer 37: 235-240, 2002.

4. Jimenez RE, Wallis T and Visscher DW: Centrally necrotizing carcinomas of the breast: a distinct histologic subtype with aggressive clinical behavior. Am J Surg Pathol 25: 331-337, 2001

5. Livasy CA, Karaca G, Nanda R, et al: Phenotypic evaluation of the basal-like subtype of invasive breast carcinoma. Mod Pathol 19: 264-271, 2006.

6. Hiltzik D, Carlson DL, Tuttle RM, Chuai S, et al: Poorly differentiated thyroid carcinomas defined on the basis of mitosis and necrosis: a clinicopathologic study of 58 patients. Cancer 106 : 1286-1295, 2006.

7. Pollheimer MJ, Kornprat P, Lindtner RA, et al: Tumour necrosis is a new promising prognostic factor in colorectal cancer. Hum Pathol 41: 1749-1757, 2010

8. Richards CH, Roxburgh CS, Anderson JH, et al: Prognostic value of tumour necrosis and host inflammatory responses in colorectal cancer. Br J Surg 99: 287-294, 2012.

9. Hiraoka N, Ino Y, Sekine S, et al: Tumour necrosis is a postoperative prognostic marker for pancreatic cancer patients with a high interobserver reproducibility in histological evaluation. Br J Cancer 103: 1057-1065, 2010.

10. Lam JS, Shvarts O, Said JW, Pantuck AJ, et al: Clinicopathologic and molecular correlations of necrosis in the primary tumour of patients with renal cell carcinoma. Cancer 103: 2517-2525, 2005.

11. Leibovich BC, Blute ML, Cheville JC, Lohse CM, Frank I, Kwon ED, et al: Prediction of progression after radical nephrectomy for patients with clear cell renal cell carcinoma: a stratification tool for prospective clinical trials. Cancer 97: $1663-1671,2003$

12. Sengupta S, Lohse CM, Leibovich BC, et al: Histologic coagulative tumour necrosis as a prognostic indicator of renal cel carcinoma aggressiveness. Cancer 104: 511-520, 2005

13. Katz MD, Serrano MF, Grubb RL 3rd, et al: Percent microscopic tumour necrosis and survival after curative surgery for renal cell carcinoma. J Urol 183: 909-914, 2010.

14. Delahunt B, McKenney JK, Lohse CM, et al: A novel grading system for clear cell renal cell carcinoma incorporating tumor necrosis. Am J Surg Pathol 37: 311-322, 2013.

15. Pichler M, Hutterer GC, Chromecki TF, et al: Histologic tumour necrosis is an independent prognostic indicator for clear cell and papillary renal cell carcinoma. Am J Clin Pathol 137: 283-289, 2012.

16. Pichler M, Hutterer GC, Chromecki TF, Pummer K, Mannweiler S and Zigeuner R: Presence and extent of histological tumour necrosis is an adverse prognostic factor in papillary type 1 but not in papillary type 2 renal cell carcinoma. Histopathology 62 : 219-228, 2013

17. Jain RK and Carmeliet PF: Vessels of death or life. Sci Am 285 38-45, 2001.

18. Weidner N: Tumour vascularity and proliferation: clear evidence of a close relationship: J Pathol 189: 297-299, 1999.

19. Kerr JF, Wyllie AH and Currie AR: Apoptosis: a basic biological phenomenon with wideranging implications in tissue kinetics. $\mathrm{Br}$ J Cancer 26: 239-257, 1972 .

20. Majno G and Joris I: Apoptosis, oncosis, and necrosis. An overview of cell death. Am J Pathol 146, 3-15, 1995.

21. Kroemer G, El-Deiry WS, Golstein P, et al; Nomenclature Committee on Cell Death: Classification of cell death: recommendations of the Nomenclature Committee on Cell Death. Cell Death Differ 12 (Suppl 2): 1463-1467, 2005.

22. Galluzzi L, Vitale I, Abrams JM, Alnemri ES, Baehrecke EH, Blagosklonny MV, et al: Molecular definitions of cell death subroutines: recommendations of the Nomenclature Committee on Cell Death 2012. Cell Death Differ 19: 107-120, 2012.
23. Kroemer G, Galluzzi L, Vandenabeele P, Abrams J, Alnemri ES, Baehrecke EH, et al; Nomenclature Committee on Cell Death 2009: Classification of cell death: recommendations of the Nomenclature Committee on Cell Death 2009. Cell Death Differ 16: 3-11, 2009.

24. Vanlangenakker N, Vanden Berghe $\mathrm{T}$ and Vandenabeele $\mathrm{P}$ Many stimuli pull the necrotic trigger, an overview. Cell Death Differ 19: 75-86, 2012.

25. Al-Nafussi AI and Hughes DE (eds): Histological patterns of tumours and tumour-like conditions. In: Histological Diagnosis of Tumours by Pattern Analysis. Arnold, London, pp11-18, 1997.

26. Hasebe T, Sasaki S, Imoto S, Mukai K, Yokose T and Ochiai A Prognostic significance of fibrotic focus in invasive ductal carcinoma of the breast: a prospective observational study. Mod Pathol 15: 502-516, 2002.

27. Nishimura R, Hasebe T, Tsubono Y, et al: The fibrotic focus in advanced colorectal carcinoma: a hitherto unrecognized histological predictor for liver metastasis. Virchows Arch 433: $517-522,1998$

28. Watanabe I, Hasebe T, Sasaki S, et al: Advanced pancreatic ductal cancer: fibrotic focus and beta-catenin expression correlate with outcome. Pancreas 26: 326-333, 2003.

29. Jass JR: Classification of colorectal cancer based on correlation of clinical, morphological and molecular features. Histopathology 50: 113-130, 2007

30. Caruso RA, Napoli P, Nania A, Parisi A, Fedele F and Zuccalà V: Mitochondrion-rich differentiated adenocarcinomas of the stomach: clinicopathological, immunohistochemical and electron microscopy study of nine cases. Virchows Arch 456: 499-505, 2010

31. Caruso RA, Fedele F, Finocchiaro G, et al: Microvascular changes in human gastric carcinomas with coagulative necrosis: an ultrastructural study. Ultrastruct Pathol 32: 184-188, 2008.

32. Caruso RA, Fedele F, Rigoli L, et al: Apoptotic-like tumour cells and apoptotic neutrophils in mitochondrion-rich gastric adenocarcinomas: a comparative study with light and electronmicroscopy between these two forms of cell death. Rare Tumours 5: 68-71, 2013.

33. Dutta S, Going JJ, Crumley AB, et al: The relationship between tumour necrosis, tumour proliferation, local and systemic inflammation, microvessel density and survival in patients undergoing potentially curative resection of oesophageal adenocarcinoma. Br J Cancer 106: 702-710, 2012.

34. Watanabe $Y$, Shimizu M, Itoh $T$ and Nagashima $K$ : Intraglandular necrotic debris in gastric biopsy and surgical specimens. Ann Diagn Pathol 5: 141-147, 2001.

35. Caruso RA, Rigoli L, Parisi A, et al: Neutrophil-rich gastric carcinomas: light and electron microscopic study of 9 cases with particular reference to neutrophil apoptosis. Ultrastruct Pathol 37: 164-170, 2013.

36. Flint A and Lloyd RV: Pulmonary metastases of colonic carcinoma. Distinction from pulmonary adenocarcinoma. Arch Pathol Lab Med 116: 39-42, 1992.

37. Greenson JK, Bonner JD, Ben-Yzhak O, et al: Phenotype of microsatellite unstable colorectal carcinomas: Well-differentiated and focally mucinous tumours and the absence of dirty necrosis correlate with microsatellite instability. Am J Surg Pathol 27: 563-570, 2003

38. Reid MD, Basturk O, Thirabanjasak D, et al: Tumour-infiltrating neutrophils in pancreatic neoplasia. Mod Pathol 24: 1612-1619, 2011.

39. Leteurtre E, Zerimech F, Piessen G, et al: Relationships between mucinous gastric carcinoma, MUC2 expression and survival. World J Gastroenterol 12: 3324-3331, 2006.

40. Baehrecke EH: Growth control: p53, the guardian angel of compensatory proliferation. Curr Biol 16: R840-R842, 2006.

41. Castedo M, Perfettini JL, Roumier T, Andreau K, Medema R and Kroemer G: Cell death by mitotic catastrophe: a molecular definition. Oncogene 23: 2825-2837, 2004

42. Ianzini F, Bertoldo A, Kosmacek EA, Phillips SL and Mackey MA: Lack of $\mathrm{p} 53$ function promotes radiation-induced mitotic catastrophe in mouse embryonic fibroblast cells. Cancer Cell Int 6: 11, 2006.

43. Mackey MA and Ianzini F: Enhancement of radiation-induced mitotic catastrophe by moderate hyperthermia. Int J Radiat Biol 76: 273-280, 2000.

44. Roninson IB, Broude EV and Chang BD: If not apoptosis, then what? Treatment-induced senescence and mitotic catastrophe in tumour cells. Drug Resist Updat 4: 303-313, 2001. 
45. Caruso R, Fedele F, Lucianò R, et al: Mitotic catastrophe in malignant epithelial tumours: the pathologist's viewpoint. Ultrastruct Pathol 35: 66-71, 2011.

46. Caruso RA, Fedele F, Crisafulli C, et al: Abnormal nuclear structures (micronuclei, nuclear blebs, strings, and pockets) in a case of anaplastic giant cell carcinoma of the thyroid: an immunohistochemical and ultrastructural study. Ultrastruct Pathol 35: 14-18, 2011.

47. Caruso RA, Rigoli L, Fedele F, et al: Modifications of nuclear envelope in tumour cells of human gastric carcinomas: an ultrastructural study. Anticancer Res 30: 699-702, 2010.

48. Caruso RA, Fedele F, Consolo P, Luigiano C, Venuti A and Cavallari V: Abnormal nuclear structures (micronuclei, nucleoplasmic bridges, and nuclear buds) in a pleomorphic giant cell carcinoma of the stomach. Ultrastruct Pathol 32: 11-15, 2008.

49. Morse DL, Gray H, Payne CM and Gillies RJ: Docetaxel induces cell death through mitotic catastrophe in human breast cancer cells. Mol Cancer Ther 4: 1495-1504, 2005.

50. Swanson PE, Carroll SB, Zhang XF and Mackey MA: Spontaneous premature chromosome condensation micronucleus formation, and non-apoptotic cell death in heated HeLa S3 cells. Ultrastructural observations. Am J Pathol 146: 963-971, 1995
51. McCluggage WG, Lyness RW, Atkinson RJ, et al: Morphological effects of chemotherapy on ovarian carcinoma. J Clin Pathol 55: 27-31, 2002.

52. Honkoop AH, Pinedo HM, De Jong JS, et al: Effects of chemotherapy on pathologic and biologic characteristics of locally advanced breast cancer. Am J Clin Pathol 107: 211-218, 1997.

53. Carder P: Typing breast cancer following primary chemotherapy. Histopathology 35: 584-585, 1999.

54. Spivak JL: The anaemia of cancer: death by a thousand cuts. Nat Rev Cancer 5: 543-555, 2005.

55. Caro JJ, Salas M, Ward A and Goss G: Anemia as an independent prognostic factor for survival in patients with cancer: a systemic, quantitative review. Cancer 91: 2214-2221, 2001.

56. Leek RD, Landers RJ, Harris AL and Lewis CE: Necrosis correlates with high vascular density and focal macrophage infiltration in invasive carcinoma of the breast. Br J Cancer 79: 991-995, 1999.

57. Tollefson MK, Thompson RH, Sheinin Y, et al: Ki-67 and coagulative tumour necrosis are independent predictors of poor outcome for patients with clear cell renal cell carcinoma and not surrogates for each other. Cancer 110: 783-790, 2007.

58. Proskuryakov SY and Gabai VL: Mechanisms of tumour cell necrosis. Curr Pharm Des 16: 56-68, 2010. 